\title{
Perspectives from Young Children on the Margins
}

\section{Guest Editors: Jane Murray and Colette Gray}

In many ways, people across the world are more connected now than they have ever been. Global non-governmental organisations and international government summits bring people together to address issues and make decisions that impact on us all. In our own field of early childhood we see evidence of globalisation affecting young children, for example large comparative studies inform international policies, and we are witnessing a trend towards global monitoring, including the OECD's forthcoming International Early Learning and Child Well-Being Study (IELS), a development that has attracted contention. Social media, $24 / 7$ news, more affordable air travel and transnational companies add to an apparently connected global environment that our digitally-native young children enter from birth.

Conversely, it may be argued that the world's people are becoming less connected. The convenience of digital communication may lead to fewer face-to-face engagements, whilst economic pressures mean many children are separated from their parents for extended periods, spending long days in professional day care or years with grandparents while their parents work in cities far from home: a common practice among rural families living in China. Our post-truth world has resulted in mistrust between policymakers and the people they serve, whilst increasing immigration has led to some rich countries adopting a protectionist stance that transforms collaboration into separatism.

The EECERA Young Children's Perspectives Special Interest Group (YCPSIG) has begun to consider these issues and their potential effects on young children. Our vibrant group brings together international researchers in the field of early childhood. Its purpose is to support and encourage cross-national perspectives on seeking children's perspectives, to support our members' research in a collaborative and cooperative manner, to generate critical reflection on children's perspectives and children's rights and to share innovative and reflexive research on children's perspectives and children's rights. The YCPSIG purpose draws heavily on Article 12 of the United Nations Convention on the Rights of the Child:

'States Parties shall assure to the child who is capable of forming his or her own views the right to express those views freely in all matters affecting the child, the views of the child being given due weight in accordance with the age and maturity of the child'. Yet the YCPSIG pushes at the boundaries of ways that 'due weight' might be accorded to the views of the youngest citizens. 
At our 2014 YCPSIG meeting at EECERA conference in Crete we began to discuss our concerns regarding some alarming evidence of disconnectedness: the increase in numbers of refugee and migrant children emerging from Syria. By the time of our 2015 summer meeting, we noted an exponential rise in refugee and migrant children entering Europe from the Middle East, the western Balkans, Africa and South Asia, a situation which continues at the time of writing. Many thousands of those children have been fleeing conflict in their home countries, of whom many are unaccompanied; many have been detained in appalling conditions and many have gone missing.

In our discussions, the YCPSIG considered particular challenges that young children might face as new arrivals. We troubled the possibility that newly arrived young children may find their new contexts alien: different from familiar places and people left behind. These displaced children have often experienced trauma yet may experience further distress by sensing they are located at the margins of their new contexts and regarded as 'other'. Given the widely recognised importance of a feeling of belonging for young children's well-being and development of identity, this possibility is of great concern to the YCPSIG group. Yet we recognise that such feelings are not only the experiences of the significant numbers of refugee and migrant young children we are currently seeing in Europe: they can also be existential for any young child experiencing liminality, rather than the feeling of belonging that lies at the core of social inclusion.

The YCPSIG wanted to explore these possibilities in ways that would value children's own expertise concerning their experiences so a Call for Papers was made for an EECERJ special issue focused on Perspectives from Young Children on the Margins. The ten articles in this special issue are the result: a carefully curated collection of leading edge empirical studies that shine a light on the diverse experiences of some young children who are on the margins. Some of the articles draw directly from the voices of young children, whilst others feature the voices of adults acting as advocates for the young children in their lives.

The special issue opens with three articles that explore themes concerning young children experiencing poverty: "Seen but not heard". Practitioners work with poverty and the organizing out of disadvantaged children's voices and participation in the early years' is the result of a collaborative project between Donald Simpson, Eunice Lumsden and Rory McDowall Clark in the UK and Sandra Loughran, Philip Mazzocco and Christian Winterbottom in the USA. The team explored ways that early childhood practitioners' engagements in a 'Pedagogy of Listening' with young children who are 
experiencing socio-economic disadvantage in the USA and the UK can offset the negative effects of the children's poverty. However, Simpson et al. report findings that suggest an increasingly prevalent technocratic approach to early childhood provision inhibits such practice. The next article in the special issue comes from an Australian team. In 'Flourishing on the margins: A study of babies and belonging in an Australian Aboriginal community childcare centre', Linda J. Harrison, Jennifer Sumsion, Ben Bradley, Karen Letsch, and Andi Salamon note that negative effects of colonisation in Australia have included long term socio-economic disadvantage and racial discrimination experienced by indigenous Aboriginal and Torres Strait Islander peoples. The article reports findings from their study conducted in a multifunctional Aboriginal children's service which elucidate ways that everyday interactions between educators and children highlighted Aboriginal concepts including children caring for one other, attachments with multiple caregivers and 'the strong child'. Claire O'Rourke's article "'Little bit afraid 'til I found how it was": Children's subjective early school experiences in a disadvantaged community in Ireland' reports on a study in which 26 children in their first year of school in a disadvantaged community in Ireland shared their perspectives about their school experiences. Four key themes emerged from semi-structured questions and a draw-and-talk activity conducted with the children.

The two articles that follow include young children's perspectives of their experiences at home and at school. Jane Murray's article 'Welcome in! How the academy can warrant recognition of young children as researchers' contests the academy's tendency to marginalise young children as researchers. It draws on the Young Children As Researchers (YCAR) study which adopted a qualitative 'jigsaw' methodology to co-research with children aged four-to-eight years $(n=138)$ and the adults who cared for them in their settings and at home in England. The article discusses the study's finding that epistemological factors and epistemological categories presented in participating young children's everyday activities and that these supported their research behaviours. It is argued that this finding warrants the academy's recognition of young children's rights as researchers with strong potential to inform early childhood policy and practice. Katrien Van Laere and Michel Vandenbroeck's article 'Early learning in preschool: meaningful and inclusive for all? Exploring perspectives of migrant parents and staff' reveals the perspectives of pre-school staff and migrant parents: two key groups of advocates for young children living in socio-economically disadvantaged conditions who are at risk of school failure in Belgium. Focus group data elicited pre-school staff and migrant parents' perspectives on young children's early learning and these carry potent messages about the value of partnership work to promote young migrant children's social inclusion. 
Children's experiences of therapeutic support are evident in the next two articles. In their article 'Do Young Children Perceive Change in the Daily Lives of their Families during Participation in a Therapeutic Family Support Program?', Kelly Baird and Rebekah Grace report on a longitudinal study conducted in Australia that explored three-to-five year old children's perceptions of their quotidian home and family lives. The children were participating in an intensive, therapeutic family support program in a disadvantaged urban community and the program was conducted with two groups of children attending either a supported playgroup or a pre-school. Findings revealed differences in the groups' perceptions of home life and as the study progressed, the perceptions of one group changed. The authors use their findings as a basis to argue that children's voices should be included in research on parenting intervention and family support programs. Sue Gascoyne reports on a study conducted with young children experiencing play therapy in England. In her article 'Patterns and Attributes in Vulnerable Children's Messy Play', she reports findings from a study that explored how young children who have experienced trauma may use their engagements in messy play to regulate and express their emotions in a therapeutic environment were observed. The children's adoptions of patterns, special attributes and transformative qualities in their interactions with resources including inter alia sand, water, gloop, clay and shaving foam, suggest that messy play was a conduit for their communication. Whilst the research data were gathered in therapeutic contexts, the author argues that the study findings have potential value for practitioners working in mainstream early childhood settings.

The final set of three articles in this special issue focus on the perspectives of children experiencing new environments. The first is an article based on research conducted in Norway: 'Here We Like Playing Princesses - Newcomer migrant children's transitions within day care: Exploring role-play as an indication of suitability and home and belonging'. Kris Kalkman and Alison Clark explore a newcomer migrant girl's transition into mainstream day care, following an experience in an introductory group for migrant children. By focusing on her role play which reveals her reconstructions of home and belonging, the authors conceptualise suitability to consider the role that cultural references may play in migrant children's transitioning into a new space. Second in this group of articles is the report of a study conducted in Israel by Nira Wahle, Yael PonizovskyBergelson, Yael Dayan, Orly Erlichman and Dorit Roer-Strier. 'On the Margins of Racism, Immigration and War: Perspectives on Risk and Protection of Young Children of Ethiopian Origin in Israel' focuses on 30 children of Ethiopian origin, aged four-to-six years, who were part of an Ethiopian immigrant community in Israel. Using images and group discussions, participating children shared their perspectives on protection and risk regarding political conflict, war, exclusion, and immigration. The 
Israeli team's findings indicate the value of a child-centred approach for exploring and understanding the experiences of children experiencing liminality. Colette Gray is the author of the final article in this special issue: 'Crossing cultural barriers: Children's views on the recuperative holiday experience'. The article explores the perspectives of four Russian-speaking children aged seven-to-eight years who experienced a recuperative holiday in Northern Ireland and the perspectives of their English-speaking host families. The children came from homes near Chernobyl, Belarus, where a high incidence of cancer prevails among the population following the release of radioactive material as the result of the 1986 nuclear power plant explosion. Findings provide valuable insights into the relationships between the children and host families.

This special issue reveals 'Perspectives from Young Children on the Margins' in varied contexts to challenge assumptions regarding the capacities and competences of young children to articulate their perspectives. We commend its articles to you as provocations to inspire further debate and discourse. They confirm the value of the United Nations right of the child that 'States Parties shall assure to the child who is capable of forming his or her own views the right to express those views freely in all matters affecting the child', yet they also provide evidence that young children's views deserve to be accorded 'due weight', regardless of the 'age and maturity of the child'. Eliciting and genuinely listening to young children's perspectives becomes especially important when young children are located on the margins. Such practice can act as a tool to build understanding that has the potential to connect those young children with their social contexts in ways that can transform their experiences of liminality to authentic feelings of belonging.

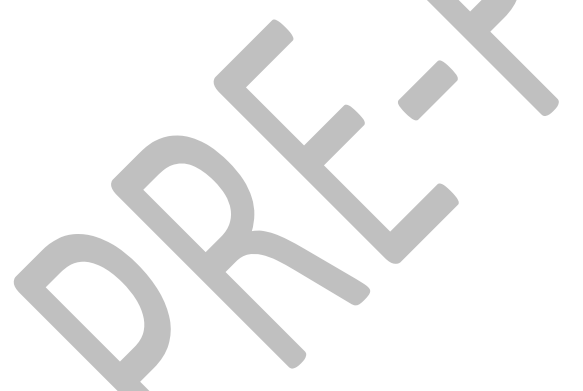

Jane Murray, $\mathrm{PhD}^{1}$ and Colette Gray, $\mathrm{PhD}^{2}$

${ }^{1}$ University of Northampton, England

E-mail: jane.murray@northampton.ac.uk

${ }^{2}$ Stranmillis University College, Northern Ireland

Email: c.gray@stran.ac.uk

Acknowledgements:

The Editors would like to thank the authors and their research participants. We are also most grateful to the reviewers, Professor Chris Pascal, Sarina Razzak, Professor Tony Bertram and Professor Júlia Formosinho at EECERJ. 